\title{
Effect of Fe nanoparticle on growth and glycolipid biosurfactant production under solid state culture by marine Nocardiopsis sp. MSA13A
}

\author{
George Seghal Kiran ${ }^{1 *}$, Lipton Anuj Nishanth ${ }^{2}$, Sethu Priyadharshini ${ }^{1}$, Kumar Anitha ${ }^{1}$ and Joseph Selvin ${ }^{2}$
}

\begin{abstract}
Background: Iron is an essential element in several pathways of microbial metabolism, and therefore low iron toxicity is expected on the usage of Fe nanoparticles (NPs). This study aims to determine the effect of Fe NPs on biosurfactant production by marine actinobacterium Nocardiopsis sp. MSA13A under solid state culture. Foam method was used in the production of Fe NPs which were long and fiber shaped in nature.

Results: The SEM observation showed non toxic nature of Fe NPS as no change in the morphology of the filamentous structure of Nocardiopsis MSA13A. The production of biosurfactant by Nocardiopsis MSA13A under solid state culture supplemented with Fe NPs increased to $80 \%$ over control. The biosurfactant produced by Nocardiopsis MSA13A was characterized as glycolipid derivative which effectively disrupted the pre-formed biofilm of Vibrio pathogen.

Conclusion: The use of metal NPs as supplement would reduce the impact of non-metallic ions of the metal salts in a fermentation process. This would ultimately useful to achieve greener production process for biosurfactants. The present results are first report on the optimization of biosurfactant production under SSC using Fe NPs.
\end{abstract}

Keywords: Fe nanoparticles, Biosurfactant, Actinobacterium, Solid state fermentation, Nanoparticle-microbial interaction

\section{Background}

Production economy is a greater challenge in industrial production of biosurfactants. Successful production depends on the development of low-cost production processes and readily available raw materials which could reduce the cost of production process substantially [1]. Development of economical engineering processes and the use of low cost feedstock for microorganism growth and surfactant production could reduce the production cost [2]. It is a well-known fact that microorganisms are immensely affected by conditions that prevail surrounding them. Variations in carbon and nitrogen sources along with its stabilization at different $\mathrm{pH}$ and temperature have resulted in increased yield of biosurfactants. Metal supplementation was reported to be one of the critical factors required for enhanced production of biosurfactants [3]. Among the metal ions, Fe is the key microelement for biosurfactant production in several microorganisms [4].

\footnotetext{
* Correspondence: seghalkiran@gmail.com

'Department of Food Science and Technology, Pondicherry University, Puducherry 605014, India

Full list of author information is available at the end of the article
}

Based on our previous bioprocess optimization for production of biosurfactants by marine actinobacteria $[5,6]$, it was established that metal ions such as $\mathrm{FeCl}_{3}, \mathrm{CuSO}_{4}$, $\mathrm{MnCl}_{2}$, and $\mathrm{MgSO}_{4}$ had significantly influenced biosurfactant production. Among the metal ions screened, $\mathrm{FeCl}_{3}$ was most appropriate metal precursor for the production of biosurfactant by marine actinobacteria followed by $\mathrm{CuSO}_{4}$. Makkar and Cameotra [7] reported that the biosurfactant production increased considerably (almost double) by the addition of metal supplements. Considering the significant role of metal ion on biosurfactant production, the present study was initiated to evaluate the effect of metal $\left(\mathrm{Fe}^{3+}\right)$ NPs on biosurfactant production.

Nanoparticles (NPs) have been hypothesized to be influence microbial production, growth and survival. Previous reports evidenced the effect of different NPs on the growth and secondary metabolite production in various microorganisms $[8,9]$. But reports revealed that NPs like Ag, $\mathrm{Au}$ and oxides of $\mathrm{Al}, \mathrm{Ti}, \mathrm{Si}$ and $\mathrm{Zn}$ have detrimental effect on the cells of microorganisms [10]. Fe was considered as an essential element with many other novel properties, such as enhanced surface-to- 
volume ratio, super-paramagnetism and inherent biocompatibility $[11,12]$. Because of using Fe atom in several pathways of metabolism, low iron toxicity is expected on the usage of Fe NPs [13,14]. In this background, the present study aims to determine the effect of Fe NPs on biosurfactant production by marine actinobacterium under solid state culture (SSC).

\section{Results and discussion}

\section{Isolation and identification of biosurfactant producer} MSA13A

This report is an outcome of bioprospecting of actinobacteria associated with marine sponge Dendilla nigra. Among the 57 stable isolates (MSA01-MSA057), the strains MSA04, MSA10, MSA13A, MSA19 and MSA21 were considered as potential biosurfactant producers. In the present study, we report the biosurfactant production potential of MSA13A. The results of screening tests performed on MSA13A include hemolytic activity (6 mm), oil displacement $(10 \mathrm{~mm})$, lipase activity $(72 \mathrm{U} /$ $\mathrm{mg})$, positive drop collapsing test and emulsification activity (23\%). The isolate hydrolyzed starch, gelatin, chitin, cellulose and tributyrin. The $16 \mathrm{~S}$ rRNA sequence of the isolate MSA13A was further analyzed using NCBI BLASTn tool with a query to limit the search for closest biosurfactant producing relatives. Representatives of maximum homologous sequences from the search were used for the construction of phylogenetic tree using UPGMA algorithm. The isolate MSA13A showed clustering with prominent biosurfactant producers Bacillus and Pseudomonas. These findings revealed that the isolate MSA13A was an actinobacterial strain producing extracellular biosurfactants. Based on the homology and similarity, the isolate was classified as Nocardiopsis sp. MSA13A. Sponge-associated actinobacteria have been reported to be prolific source of secondary metabolite producers $[15,16]$ and suggested to attribute largely to the chemical defense mechanisms of their host sponges against predators with biologically active compounds (repellents) and biofouling ([17] and references therein).

\section{Interaction of NPs with actinobacterium}

Foam method was used in the production of Fe NPs which were long and fiber shaped in nature (Figure 1A). The diameter of the synthesized Fe NPs was about $40 \mathrm{~nm}$ and they were around $1 \mu \mathrm{m}$ in length. The SEM results showed fibrous shape of the Fe NPs along with their approximate size. EDS analysis evidenced iron to be the metal in Fe NPs synthesized (Figure 1C). Absence of oxygen indicated that the Fe NPs had not undergone oxidation even though mild exposure to air during the synthesis process. UV-vis spectroscopy of Fe NPs showed an absorption peak at $230 \mathrm{~nm}$ (data not shown). Fe NPs obviously show peaks at $216 \mathrm{~nm}$ and $268 \mathrm{~nm}$ in distilled water [18]. The strong absorbance obtained at a wavelength $<250 \mathrm{~nm}$ indicated that the size of the Fe NPs synthesized was $<40 \mathrm{~nm}$. It was observed that the highest densities of colonies were appeared on the plate with $10 \mathrm{mg} / \mathrm{L}$ of Fe nanoparticle. No significant change was observed between fresh and one week old Fe NPs. Growth rate of Nocardiopsis MSA13A was induced significantly by Fe NPs at $10 \mathrm{mg} / \mathrm{L}$. The effect of Fe NPs at $100 \mathrm{mg} / \mathrm{L}$ and lower than $10 \mathrm{mg} / \mathrm{L}$ showed least or no effect on the growth of Nocardiopsis MSA13A. The reduction in cell density on addition of high concentration of Fe NPs was probably due to aggregation in the medium leading to damage of the growing cell [19-21]. The present study evidenced Fe NPs was non-toxic to actinobacterium whereas $\mathrm{Cu}$ NPs were reported to be toxic to bacterial cells [22]. Little change was observed with one week old Fe NPs indicating the variation in toxicity of the NPs probably due to their oxidation but still the overall effect had remained the same. To avoid oxidative effect on Fe NPs, the present study was carried out with freshly prepared Fe NPs. The Fe NPs positively interacted with actinobacterium which was evident from the intact filamentous morphology of Nocardiopsis MSA13A treated with $10 \mathrm{mg} / \mathrm{L}$ of Fe NPs for $4 \mathrm{~h}$ (Figure 1C).

\section{Influence of Fe NPs on biosurfactant production}

The production of biosurfactant by Nocardiopsis MSA13A was increased to $80 \%$ over control (without NPs) at $10 \mathrm{mg} / \mathrm{L}$ Fe NPs (Figure 2). It was recorded that the production of biosurfactant decreased at higher concentration of Fe NPs. The initial increase in production was due to the effect of Fe nanoparticle providing more nutrition to the organism by activation of the medium [14]. Electron donating nature of the $\mathrm{Fe}^{2+}$ ion has been studied previously which satiates the demand of the organism for electron [4]. Ehrlich [23] reported that some bacteria can acquire energy for growth from oxidation of $\mathrm{Fe}^{2+}$ to $\mathrm{Fe}^{3+}$. Fe is an important enzyme activator, specifically of isocitrate lyase, an enzyme involved in cell growth on hydrophobic substrates. This enzyme is essential for cell to modulate metabolic pathway of acetyl-CoA and convert it into a C4 unit during biosurfactant synthesis [24]. The microorganisms have developed a variety of strategies for acquiring iron while simultaneously protecting them from the potential toxicity of iron [25]. The main strategies used by bacteria and fungi to acquire iron include producing and utilizing siderophores.

\section{Optimization of biosurfactant production under SSC}

The production of biosurfactant by Nocardiopsis MSA13A was increased substantially with treated molasses (distillery waste) as substrate $\left(\mathrm{E}_{24} 35 \%\right)$ followed by tannery pretreated sludge (20\%), pre-treated molasses $(20 \%)$, tannery 

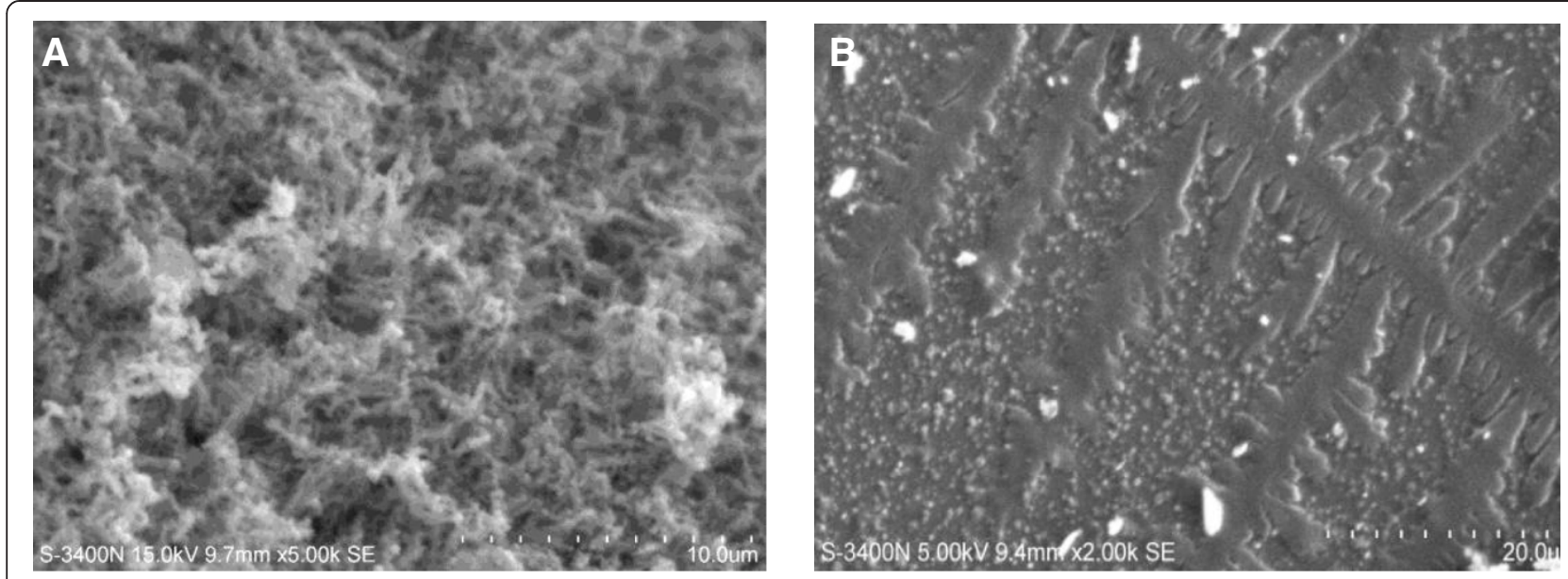

\section{C}

Base(2)

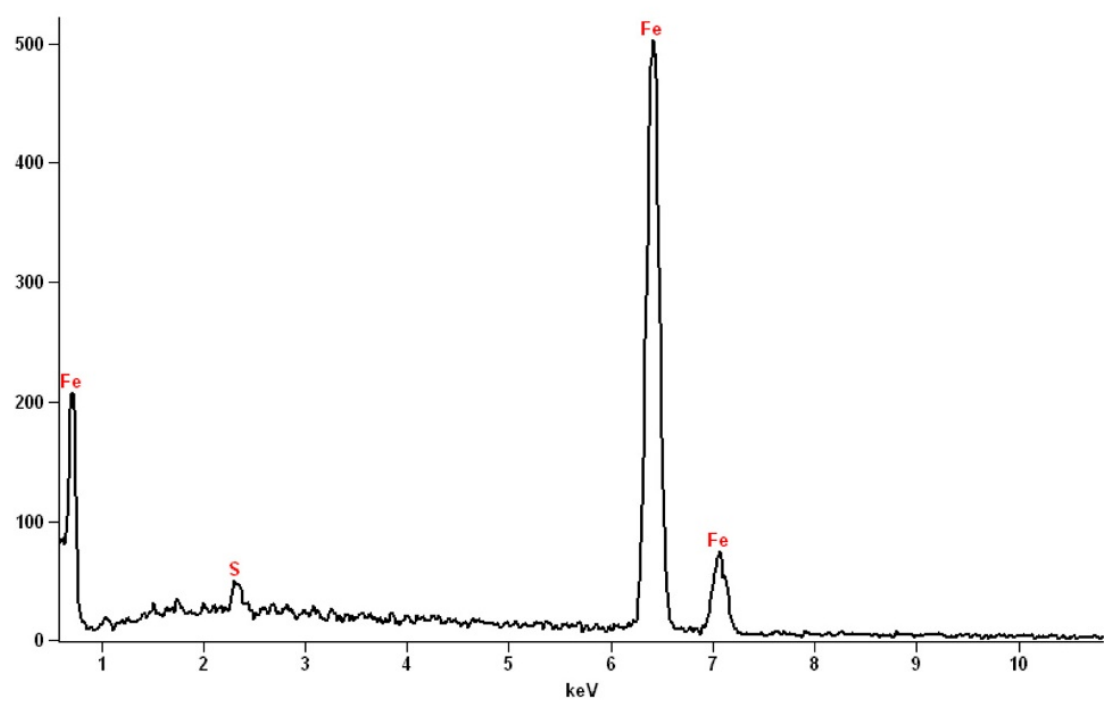

Figure 1 SEM observation of (A) fiber-shaped Fe nanoparticles (diameter nano size) synthesized using foam method (B) Nocardiopsis morphology after $4 \mathrm{~h}$ interaction with $10 \mathrm{mg} / \mathrm{L}$ Fe NPs (C) EDS analysis of freshly synthesized Fe NPs showing high percentage of iron element.

treated sludge (20\%) and wheat bran (18\%). Enhanced biosurfactant production by Nocardiopsis MSA13A under SSC was achieved with glucose as carbon source, yeast extract as nitrogen source, $\mathrm{pH} 7.0,2 \% \mathrm{NaCl}$, and asparagine as amino acid. The production of biosurfactant by Nocardiopsis MSA13A was consistently increased between $30^{\circ} \mathrm{C}$ and $40^{\circ} \mathrm{C}$. The influence of metal ions such as $\mathrm{CuSO}_{4}$, $\mathrm{MnCl}_{2}, \mathrm{MgSO}_{4}$ and $\mathrm{FeCl}_{3}$ on the production of biosurfactant by Nocardiopsis MSA13A was evaluated under SSC. Among the metal ions screened, $\mathrm{FeCl}_{3}$ was most essential metal ion for enhanced biosurfactant production by Nocardiopsis MSA13A followed by $\mathrm{CuSO}_{4}$. The strain showed maximum production on the substrate inoculated with $2.5 \mathrm{ml}$ inoculum. The moisture content required for the maximum production of biosurfactant was $>80 \%$.
Factors optimized under one-factor at a time experiments are given in supplementary figure. The strain Nocardiopsis MSA13A produced maximum biosurfactant on treated molasses with $3 \%$ glucose as carbon source and $2 \%$ yeast extract as nitrogen source (Figure 3A and B). The strain required a higher amount of carbon source compared to that of the nitrogen source concentration based on the effect of $\mathrm{C} / \mathrm{N}$ ratio.

\section{Optimization of biosurfactant production using Response Surface Methodology (RSM)}

Statistical optimization of biosurfactant production was carried out by Design-Expert software package (Stat-Ease, Inc., USA). The $\mathrm{R}^{2}$ value of 0.9406 which was closer to 1 shows the model to be stronger and it can better predict 


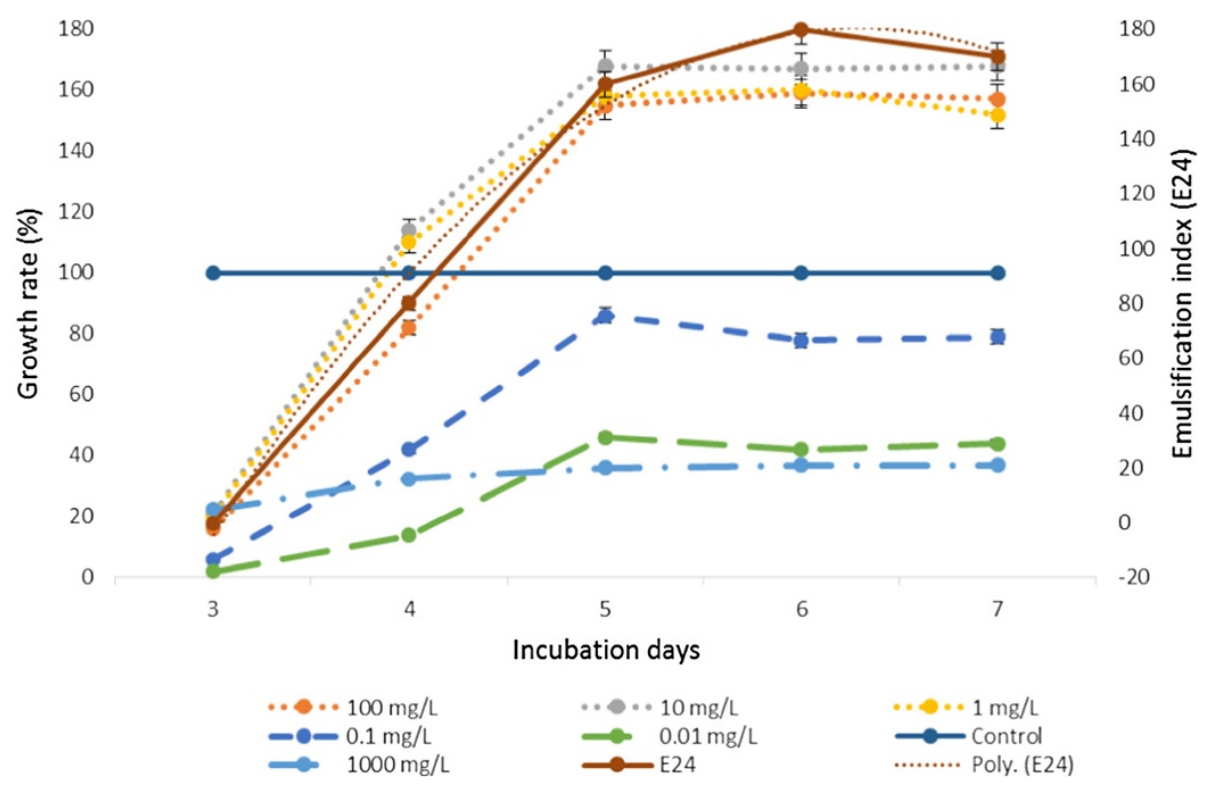

Figure 2 Effect of Fe NPs on the growth rate and biosurfactant production by Nocardiopsis MSA13A. Lag period was fall on 0 to $2 \mathrm{~d}$ which is not shown in the Figure. The growth rate was presented in terms of percent increase over the control. Growth rate was derived from colony plate count and OD values. $10 \mathrm{mg} / \mathrm{L} \mathrm{Fe} \mathrm{NPs} \mathrm{induced} \mathrm{growth} \mathrm{rate} \mathrm{of} \mathrm{Nocardiopsis} \mathrm{MSA13A} \mathrm{to} \mathrm{the} \mathrm{maximum} \mathrm{of} 67 \%$ over control. The same Fe NPs concentration increased to $80 \%$ biosurfactant production over control.

the response. The model was found to be significant with $\mathrm{p}<0.0001$ and insignificant lack of fit (Additional file 1). The behavior of the system is explained by the following quadratic model equation

$$
\begin{aligned}
\mathrm{Y}=40 & +10.67 \mathrm{X}_{1}-6.42 \mathrm{X}_{2}-11.42 \mathrm{X}_{3}-3.17 \mathrm{X}_{4}+16 \mathrm{X}_{1}^{2} \\
& +7.88 \mathrm{X}_{2}^{2}+8.88 \mathrm{X}_{3}^{2}-16.25 \mathrm{X}_{4}^{2}+6.25 \mathrm{X}_{1} \mathrm{X}_{2} \\
& +0.75 \mathrm{X}_{1} \mathrm{X}_{3}-4.5 \mathrm{X}_{1} \mathrm{X}_{4}+2.5 \mathrm{X}_{2} \mathrm{X}_{3}-3.0 \mathrm{X}_{2} \mathrm{X}_{4} \\
& -1.5 \mathrm{X}_{3} \mathrm{X}_{4}
\end{aligned}
$$

\section{Validation of the model}

The predicted value of $\mathrm{Y}$ by the above explained quadratic model was found to be $72 \%$. The experimental value obtained was $83 \%$. The difference in the predicted and the experimental value can be attributed to Fe NPs. The Fe NPs might have induced the metabolic pathway of biosurfactant synthesis. It was found that the production was significantly influenced by the variables such as glucose, yeast extract, Fe NPs and inoculum size either interactively and/or independently. A significant interactive influence of primary control factors such as glucose and yeast extract was validated in the RSM design. The glucose and yeast extract interactively reached a central value to influence the production maxima over a stable area (Figure 4A). The Fe NPs and inoculum size interactively increase the production and the stable production was attained with the influence of both factors independently (Figure 4B). The present results are first report on the optimization of biosurfactant production using Fe NPs.

\section{Chemical characterization of biosurfactant}

Based on the TLC analysis, carbohydrate and lipid fractions were separated. The FT-IR spectra (Figure 5A) and GC-MS data (Figure $5 \mathrm{~B}$ and $\mathrm{C}$ ) showed that the compound produced by Nocardiopsis MSA13A was a glycolipid with a hydrophobic non-polar hydrocarbon chain (hexacosanoic acid, propyl ester) and hydrophilic part of the compound being a sugar methyl-4- O-methyl- $\beta-D-$ xylopyranoside. Retention times, relative intensities (\%) and EIMS of the relevant peaks are as follows: Peak A: 10.591, 30, EIMS m/z (\% rel. intensity), 87.1 (100), 79.1 (30), 76 (70), 71 (40), 60.4 (20), 58.3 (40) and 52.3 (15). Peak B: 18.058, 100, EIMS m/z (\% rel. intensity), 420 (70), 105 (20), 100 (30), 60 (60), 40 (100), 20 (15). It was established that GC-MS was a standard technique in carbohydrate analysis [26] and based on the previous reports, the peaks obtained the present study was matched with methyl-4- O-methyl- $\beta$-D-xylopyranoside.

\section{Antibiofilm activity of biosurfactant}

A prominent shrimp pathogen Vibrio aliginolyticus treated with $300 \mu \mathrm{g} / \mathrm{ml}$ of biosurfactant significantly disrupted the pre-formed biofilm (Figure 6). The biofilm disruption was indicated by the absence of visible film on the wall and bottom of the tube when the glass tube was incubated with biosurfactant $(300 \mu \mathrm{g} / \mathrm{ml})$ for $30 \mathrm{~min}$ at $28^{\circ} \mathrm{C}$. Lower concentration was effective but not 

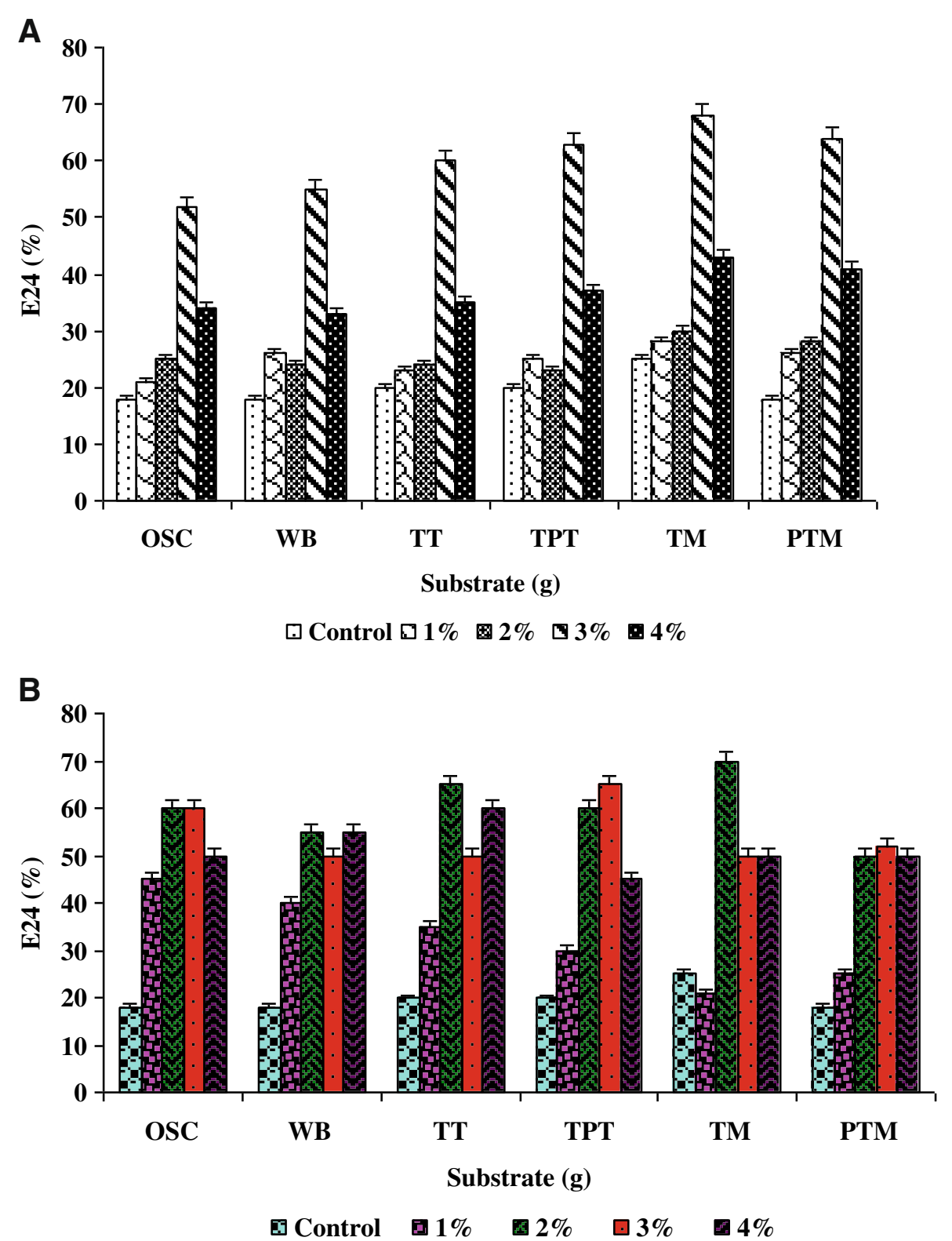

Figure 3 Effect of carbon and nitrogen sources on biosurfactant production. A) Effect of increasing concentration of optimized carbon source, glucose on the production of biosurfactant B) Effect of increasing concentration of optimized nitrogen source, yeast extract on the production of biosurfactant by Nocardiopsis MSA13A.

disrupted the biofilm completely. Vibriosis was by far the most significant factor of aquaculture loss in many countries. Vibrio is a serious pathogen of marine fish and invertebrates, particularly penaeid shrimp [27]. The finding of the present study brings out a new biosurfactant derivative from marine actinobacterium which could effectively disrupt pathogenic biofilms.

\section{Conclusion}

Identification of bacterial responses provides vital information on the influence of NPs on microorganism. Due to their tiny size and stabilization [28], as well as high surface to volume ratio nanomaterials can easily influence the growth as well as secondary metabolite production of microorganisms, but this effect is not always negative in nature. In this study Fe NPs was used to enhance biosurfactant production by actinobacterium, since $\mathrm{Fe}$ is an essential nutrient for almost all microorganisms because it plays an important role in optimum cell growth as well as cofactor for a large number of enzymes, is a part of cytochromes and is required for many biochemical reaction, including respiration, photosynthetic transport, 

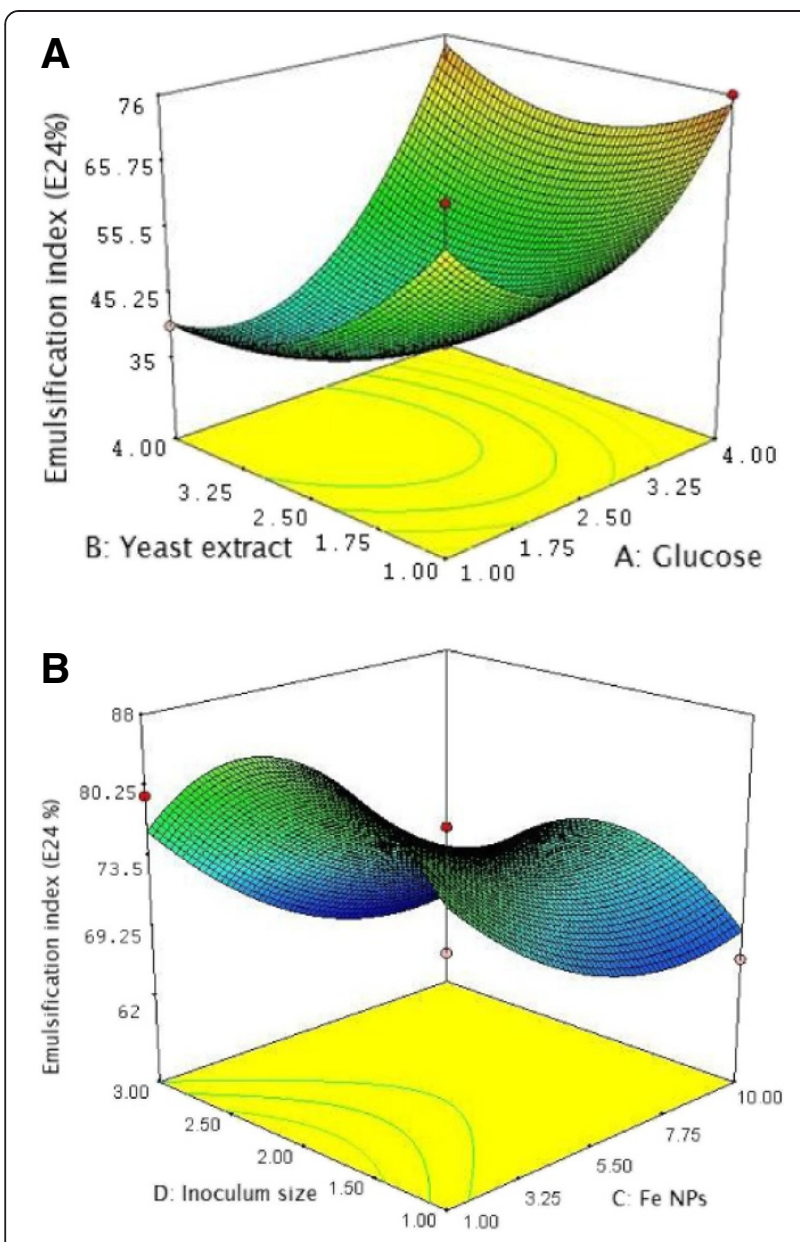

Figure $\mathbf{4}$ Statistical optimization of biosurfactant production. A. Contour plot of the interaction between the glucose (carbon source) and yeast extract (nitrogen source) on the production of biosurfactant in SSC by Nocardiopsis MSA13A. B. Contour plot of the interaction between the Fe NPs and inoculum size on the production of biosurfactant.

and DNA synthesis [29]. It has been hypothesized that the use of metal salt as supplements in the fermentation process would retain the non-metal salt ions such as $\mathrm{Cl}^{-}$ or $\mathrm{SO}_{4}^{2-}$ as impurity in the medium. Therefore, the use of metal NPs as supplement would reduce residual effect of metal salts in the fermentation products. Based on the findings, the NPs could be used as inducer of metabolic pathway of actinobacterium for enhanced production of biosurfactant under SSC. The present study evidenced that the biosurfactant can be used to effectively disrupt and/or to prevent Vibrio sp. biofilms in shrimp aquaculture.

\section{Methods}

\section{Isolation, screening and identification of marine actinobacterium}

The collection and isolation of actinobacteria from the marine sponge Dendrilla nigra was performed as per the procedure of [30]. Briefly, $1 \mathrm{~cm}^{3}$ of sponge tissue was excised from the internal mesohyl area using a pair of sterile scissors. The excised portion was homogenized with phosphate buffered saline using a tissue homogenizer. The aliquot was placed on various isolation media including marine sponge agar [31] and standard media (HiMedia). The inoculated plates were incubated at $27^{\circ} \mathrm{C}$ for 14 days in dark. The incubation temperature was reduced to achieve a near environmental temperature $\left(25^{\circ} \mathrm{C}\right)$ range prevailed at the site of sponge collection. The morphologically distinct colonies were reisolated and maintained on actinomycetes isolation agar (HiMedia) at $4^{\circ} \mathrm{C}$. The isolates were screened for biosurfactant production using drop collapsing test, oil displacement test [32], lipase activity [33], and hemolytic activity [33]. Emulsification activity was performed according to Paraszkiewicz et al. [34]. All the assays were performed in triplicate with distilled water as control. The actinomycetes isolation agar was included as negative control in the screening as to determine the effect of medium on the emulsification index of the isolate. The producer strain MSA13A was identified morphologically and biochemically according to the method of Lechevalier [35] and the genomic DNA was obtained by the method of Ferrara et al. [36]. For the $16 \mathrm{~S}$ rRNA sequencing the PCR analysis was performed as follows: Universal $16 \mathrm{~S}$ rRNA eubacterial primer $\left(5^{\prime}\right.$-GA GTTTGATCCTGGCTCAG-3'; 5' -AGAAAGGAGGTGA TCCAGCC-3') was used for the amplification of $16 \mathrm{~S}$ rRNA. The 16S rRNA gene sequence (FJ372669) obtained from the isolate MSA13A was compared with other bacterial sequences by using NCBI megaBLAST (http://blast. ncbi.nlm.nih.gov/Blast.cgi) for their pair wise identities. Phylogenetic tree was constructed in MEGA 4.0 version (www.megasoftware.net) using unweighted pair group method with arithmetic mean (UPGMA) algorithms (data not shown).

\section{Synthesis of $\mathrm{Fe}$}

Foam method was followed in the synthesis of Fe NPs chemically [14]. The NPs were synthesized in small

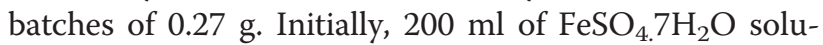
tion $(6 \mathrm{~g} / \mathrm{L})$ was prepared along with $250 \mathrm{ml}$ of the cationic surfactant CTAB (3.2 g/L). Both the solution was thoroughly mixed for $10 \mathrm{~min}$ on a magnetic stirrer. $\mathrm{NaBH}_{4}$ solution $(22 \mathrm{~g} / \mathrm{L})$ was prepared in $15 \mathrm{~mL}$ of deionised water and mixed with $\mathrm{FeSO}_{4} .7 \mathrm{H}_{2} \mathrm{O}-\mathrm{CTAB}$ solution for 15 min on a magnetic stirrer. On addition of $\mathrm{NaBH}_{4}$, the clear solution turned black in colour indicating the production of Fe NPs. The NPs were allowed to settle down for $15 \mathrm{~min}$. The solution was flushed with acetone for six times and stored in acetone.

\section{Effect of NPs on growth of marine actinobacterium}

Marine actinobacterium MSA13A (originally designated as actinobacterium MSA10) was cultured in actinomycetes 

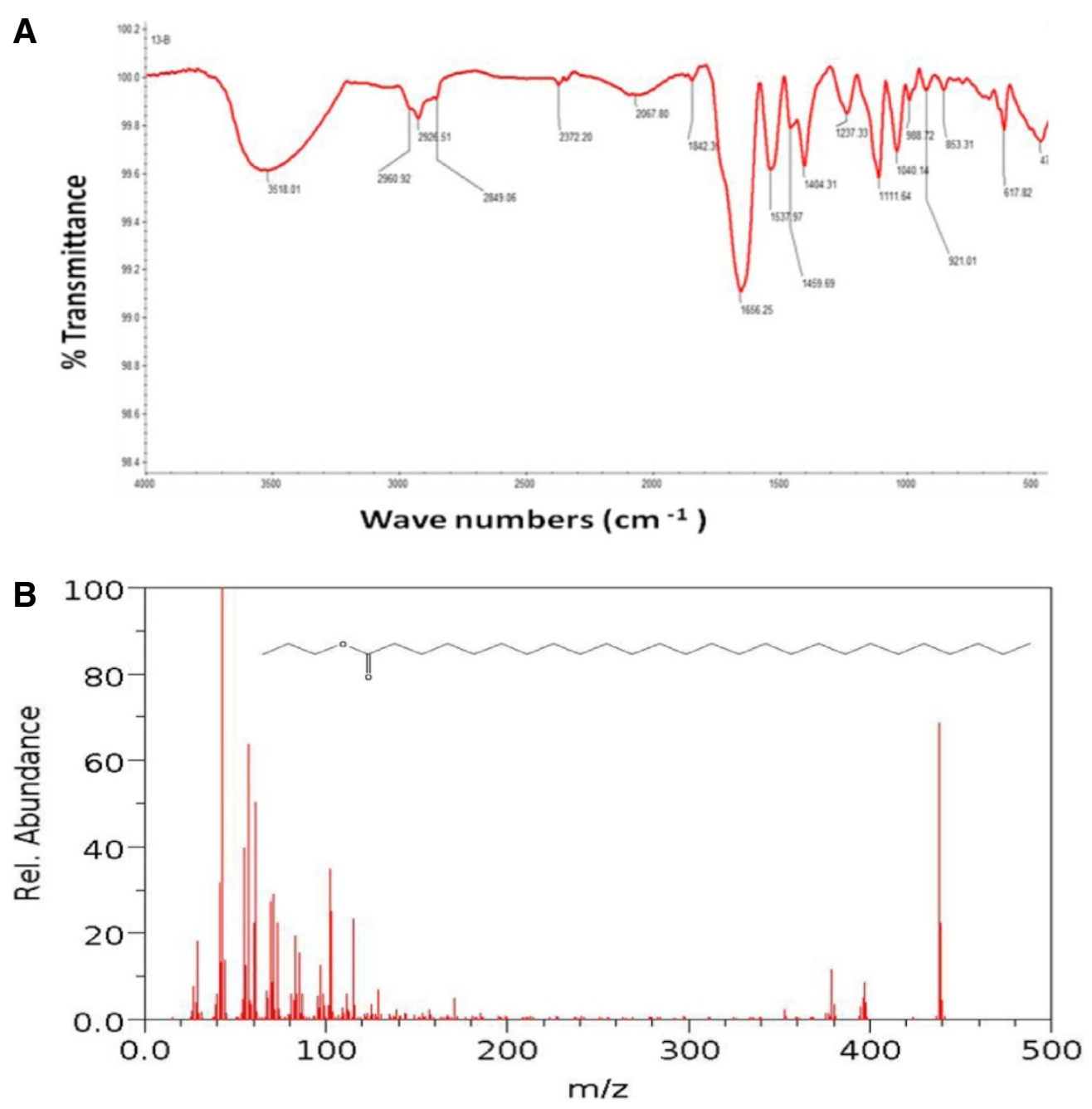

EM-57 859 (10.591) Rf (3.6.000)

C

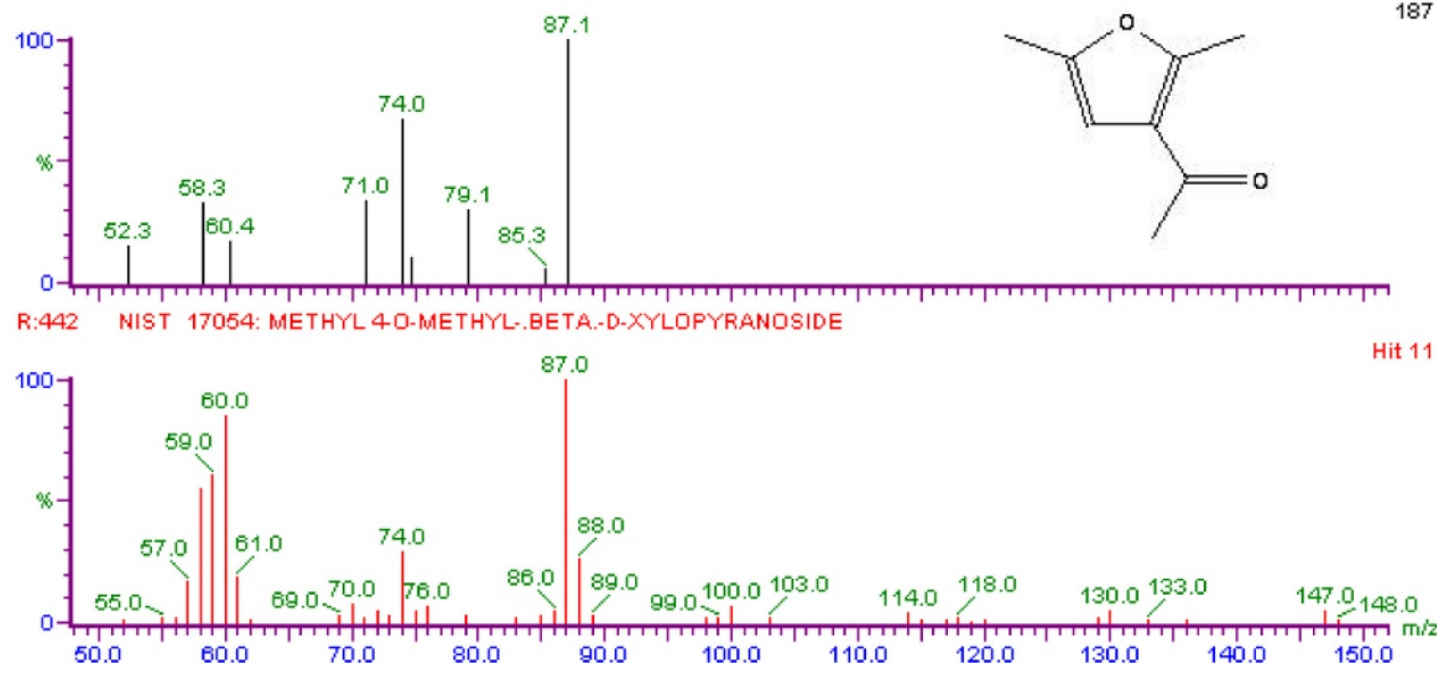

Figure 5 Purification and chemical characterization of biosurfactant. A) TLC results of carbohydrate and lipid fractions of biosurfactant.

B) MS spectra of lipid moiety of glycolipid biosurfactant showing non-polar hydrocarbon chain (hexacosanoic acid, propyl ester). C) MS spectra of sugar moiety of glycolipid biosurfactant showing methyl-4- O-methyl-beta-D-xylopyranoside. 

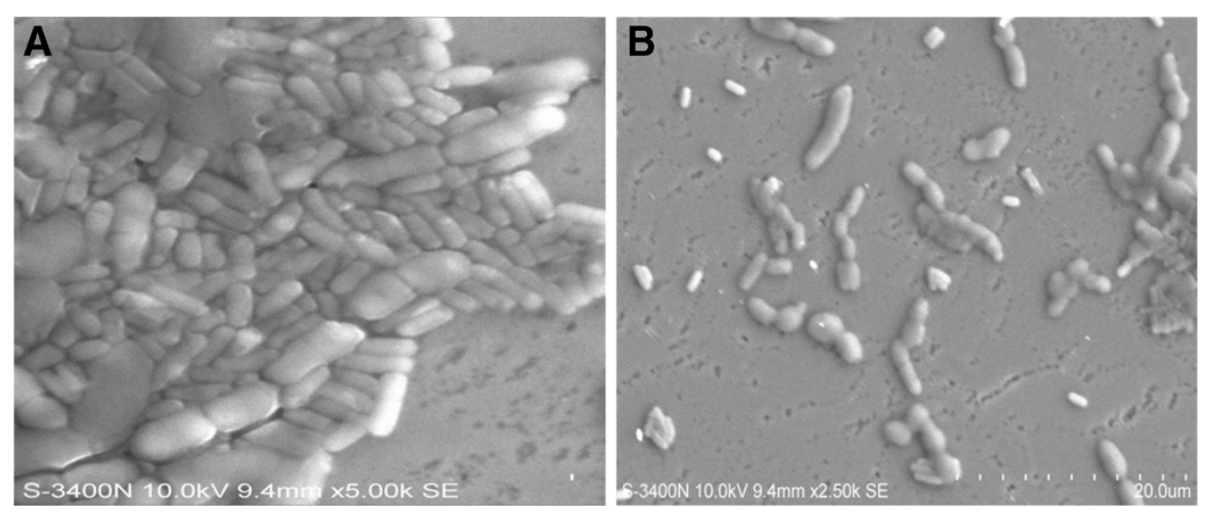

Figure 6 Effect of biosurfactant on biofilm disruption. (A) The cells were tightly bound by exopolysaccharies, shows biofilm (B) The effect of biosurfactant on the pre-formed (24 h) biofilm. The biofilm nature was disrupted and few microcolonies of Vibrio alginolyticus was remaining after the disruption of preformed biofilm by biosurfactant.

broth (Himedia) with $1 \%$ glycerol and $2 \% \mathrm{NaCl}$ at $30^{\circ} \mathrm{C}$ for $5 \mathrm{~d}$ to reach its exponential growth phase. NPs obtained by foam method were sonicated in phosphate buffered saline (PBS) for $30 \mathrm{~min}$ at $40 \mathrm{~Hz}$ until completely dispersed in the saline without any signs of agglomeration. The artificial dispersant was not used in the present study as they might interfere the interaction of NPs with biosurfactants. Freshly prepared as well as one week old Fe NPs dispersed in PBS to prepare broad range aliquots $(0.01$ to $1000 \mathrm{mg} / \mathrm{L})$ and added into the culture of exponentially growing marine actinobacteriun MSA13A. Resultant actinobacterium-nanoparticle conjugate was incubated at $30^{\circ} \mathrm{C}$ for $24 \mathrm{~h}$. The conjugate was diluted to $10^{4}$ fold and $10 \mu \mathrm{L}$ each was plated on actinomycetes agar supplemented with $2 \% \mathrm{NaCl}$ to determine growth rate by colony plate count method. After $5 \mathrm{~d}$ of incubation at $30^{\circ} \mathrm{C}$, the number of colonies on triplicate plate was counted and calculated percent growth rate over control.

\section{Influence of NPs on biosurfactant production}

The biosurfactant production was optimized in the preliminary phase under submerged fermentation $(\mathrm{SmF})$ conditions. For the $\mathrm{SmF}$, actinomycetes broth (Himedia) with trace elements - $\mathrm{ZnSO}_{4} .7 \mathrm{H}_{2} \mathrm{O}-0.29 \mathrm{~g}, \mathrm{CaCl}_{2} .4 \mathrm{H}_{2} \mathrm{O}$ $0.24 \mathrm{~g}, \mathrm{CuSO}_{4} \cdot 5 \mathrm{H}_{2} \mathrm{O}-0.25 \mathrm{~g}, \mathrm{MnSO}_{4} \cdot \mathrm{H}_{2} \mathrm{O}-0.17 \mathrm{~g} / 100 \mathrm{ml}$ were used as production medium. $500 \mathrm{ml}$ Erlenmeyer flasks containing $200 \mathrm{ml}$ of medium was inoculated with actinobacterium and incubated at $30^{\circ} \mathrm{C}$ for 7 days. Based on the SmF conditions (data not shown), the production medium without trace elements were used for determining the effect of NPs on biosurfactant production.

Biosurfactant production medium without trace elements was enriched with a broad range of Fe NPs $(0.01$ to $1000 \mathrm{mg} / \mathrm{L}$ ) and the growth rate of actinobacterium during the fermentation process was estimated based on $\mathrm{OD}$ at $600 \mathrm{~nm}$ (UV-vis spectrophotometer AU-2701). The emulsification index $\mathrm{E}_{24}$ was determined to find the effect of NPs on biodurfactant production. Briefly, olive oil was added to the cell free supernatant in a ratio of 1:1 and vortexed vigorously for $2 \mathrm{~min}$. After $24 \mathrm{~h}$ of incubation, the height of the emulsified layer was measured and compared with the total height of the liquid layer and multiplied by $100\left(E_{24}\right)$. The direct effect of NPs on the biosurfactant activity was determined based on emulsification index. The cell free supernatant was extracted at least three times with chloroform-methanol $(3: 1, \mathrm{v} / \mathrm{v})$, with $15 \mathrm{~mL}$ of this solvent mixture being used for each extraction. The organic phase was concentrated at $40^{\circ} \mathrm{C}$ in a rotary vacuum evaporator (Yamato). Various concentrations of Fe NPs were mixed with biosurfactant extracted and incubated for $24 \mathrm{~h}$. The $\mathrm{E}_{24}$ was then determined with olive oil emulsion as described above.

\section{SEM observation}

Ethanol suspensions of immediately synthesized Fe NPs were vortexed and a thin, uniform smear was prepared on the surface of a cover slip. Sample prepared was then placed on carbon tape and was sputter-coated with carbon for SEM (S-3500 N Hitachi) observation. The interaction of $\mathrm{Fe}$ nanoparticle with the actinobacterium was observed under SEM. The exponentially growing actinobacterium were centrifuged at $1000 \mathrm{rpm}$ for $10 \mathrm{~min}$. The pellet obtained was resuspended in PBS containing the dispersed $\mathrm{Fe}$ nanoparticle and this actinobacteriumnanoparticle conjugate was incubated at room $30^{\circ} \mathrm{C}$ for $4 \mathrm{~h}$. This conjugate was used to prepare thin and uniform smear on the surface of a cover slip. It was properly dehydrated and was placed into a carbon tape which was sputter-coated with carbon for SEM observation.

Energy-dispersive spectroscopy (EDS, Thermo, USA) was performed to determine the composition of the NPs. Along with freshly synthesized Fe NPs, one week old Fe NPs were also used as to find oxidative effect on the NPs. The spectral analysis was used to confirm the presence of elemental iron. It was also used to analyze 
the oxidized state of Fe NPs. Absorption spectrum of the synthesized Fe nanoparticle was measured by OD 500-900 nm scan in a UV-VIS spectrophotometer. Fe NPs were used without any dilution.

\section{Optimization of biosurfactant production under solid state culture (SSC)}

For the development of SSC, the production substrate was developed using agro-industrial and industrial waste [37]. Based on the preliminary screening results, treated molasses (distillery waste), tannery pretreated sludge, pre-treated molasses, tannery treated sludge and wheat bran were selected for optimization experiments. The substrates were dried at $60^{\circ} \mathrm{C}$ in an oven prior to SSC formulation. The bioprocess was developed as per Kiran et al. [37]. Optimization of biosurfactant production was carried out by search one at a time experiments. Factors such as carbon and nitrogen sources, $\mathrm{pH}$, temperature, amino acids, metal ions, inoculum size and salt concentration affecting the biosurfactant production were determined (Additional file 1). Subsequently response surface methods (RSM) were applied to analyze the interactions between the critical control factors [37,38]. In the RSM experiments, the ferric chloride was replaced with Fe NPs to determine the effect of NPs on biosurfactant production. The variables including glucose, yeast extract, Fe NPs and inoculum size that have effect on the production of biosurfactant were identified by the optimization experiments. Each independent variable was investigated at a high $(+1)$ middle (0) and a low $(-1)$ level. Runs of center points (control) were included in the matrix.

\section{Chemical characterization of biosurfactant}

Extraction of glycolipids was performed with $100 \mathrm{~mL}$ of distilled water added to the SSC flasks and was agitated for $1 \mathrm{~h}$ at $200 \mathrm{rpm}$ at $30^{\circ} \mathrm{C}$ on an orbital shaker. The suspension was filtered through cheesecloth, the excess liquid being squeezed out manually. This procedure was repeated three times. The extract was centrifuged for $10 \mathrm{~min}$ at $12,500 \times \mathrm{g}$, and the supernatant was extracted at least three times with $15 \mathrm{~mL}$ each of chloroformmethanol $(3: 1, \mathrm{v} / \mathrm{v})$ [39]. The organic phase was concentrated at reduced pressure at $40^{\circ} \mathrm{C}$, giving rise to a crude extract containing the glycolipids. Glycolipids were quantified in terms of rhamnose using the phenolsulfuric acid method [40] with sugar (rhamnose) as the standard. A control sample prepared from uncultured medium in order to check for interference from medium components. The presence of rhamnolipids was determined using correction factor [41]. To purify the surface active compound, the ethyl acetate extract was resolved through a column chromatography on reverse phase silica gel (230-400 mesh). Elution was performed with methanol from $65 \%$ to $100 \%$ at a flow rate of $0.5 \mathrm{ml} / \mathrm{min}$ at $30^{\circ} \mathrm{C}$. An Agilent GC-MS system equipped with a fused silica capillary tube was used to analyze the components in this active fraction. The data was processed by GC-MSD Chemstation column condition was programmed as column oven temperature $150^{\circ} \mathrm{C}(4 \mathrm{~min})-$ $4^{\circ} \mathrm{C} / \mathrm{min}$, temperature of injection port $250^{\circ} \mathrm{C}$ and detector port $280^{\circ} \mathrm{C}$. The peaks of the gas chromatography were subjected to mass-spectral analysis. The spectra were analyzed from the available library data. NIST MS search (version 2.0) (included with NIST'02 mass spectral library, Agilent p/n G1033A).

\section{Antibiofilm activity of biosurfactant}

The biofilm strains were inoculated in LB broth and incubated at $37^{\circ} \mathrm{C}$ for $24 \mathrm{~h}$. After incubation the cells were washed and resuspended in phosphate buffered saline $(\mathrm{pH} 7.2)$ to a turbidity equivalent to a $0.5 \mathrm{M} \mathrm{McFarland}$ standard. The 96- well U-bottomed microtitre plates were filled with $80 \mu \mathrm{l}$ of LB broth, $10 \mu \mathrm{l}$ of each cell suspension and $10 \mu \mathrm{l}$ of each test concentration in triplicate. The control was set with newly developed biofilm. Triplicate wells each were set with biosurfactant concentrations such as 50, $100,150,200,250$ and $300 \mu \mathrm{g} / \mathrm{ml}$. Plates were incubated on a platform shaker. After $24 \mathrm{~h}$ the planktonic cells and spent media were discarded, and adherent cells were rinsed with deionized water. Then the plates were allowed to air dry. The biofilms were stained by $200 \mu \mathrm{l}$ of $0.4 \%$ crystal violet for $10 \mathrm{~min}$. After staining the dye was discarded and the wells were rinsed twice with deionized water. The plates were air dried and $200 \mu \mathrm{l}$ of dimethylsulfoxide was added to each well. The OD was determined at $595 \mathrm{~nm}$ in a microplate reader (data not shown). The SEM analysis was performed on preformed biofilm treated with effective concentration of biosurfactant as determined in the microplate assay. The biofilm disruption was evident from SEM observation.

\section{Additional file}

Additional file 1: Table S1. Factors considered for the optimization of biosurfactant production under solid state culture (SSC). Table S2. ANOVA analysis of the optimization of production by Nocardiopsis MSA13A. Figure S1. Effect of various substrates including agro-industrial and industrial waste on the production of biosurfactant. The SSC was performed with basal medium $6 \mathrm{ml} / 250 \mathrm{ml}$ flask, substrate $5 \mathrm{~g} / 250 \mathrm{ml}$ flask and $7 \mathrm{ml} / 5 \mathrm{~g}$ substrate. Figure S2. Effect of various carbon sources on the production of biosurfactant. Figure S3. Effect of various nitrogen sources on the production of biosurfactant. Figure S4. Effect of pH on the production of biosurfactant. Figure S5. Effect of tempertaure on the production of biosurfactant. Figure S6. Effect of incubation period on the production of biosurfactant. Figure S7. Effect of metal ions on the production of biosurfactant. Figure S8. GC-MS data of purified biosurfactant fraction.

\section{Competing interests}

The authors declare that they have no competing interests.

\section{Authors' contributions}

JS designed, monitored and written the paper. ANL has performed Fe NPS synthesis and biofilm disruption part, GSK performed optimization part and 
AD and SP helped the lab experiments performed by GSK. All authors read and approved the final manuscript.

\section{Acknowledgements}

ANL is thankful to DBT for JRF. JS is thankful to Department of Biotechnology, Govt of India for research grant. This is an outcome of DBT project No. BT/PR14678/AAQ/03/538/2011.

\section{Author details}

${ }^{1}$ Department of Food Science and Technology, Pondicherry University, Puducherry 605014, India. ${ }^{2}$ Department of Microbiology, School of Life Sciences, Pondicherry University, Puducherry 605014, India.

Received: 15 October 2013 Accepted: 17 April 2014

Published: 21 May 2014

\section{References}

1. Cameotra SS, Makkar R: Synthesis of biosurfactants in extreme conditions. Appl Microbiol Biotechnol 1998, 50:520-529.

2. Khopade A, Biao R, Liu X, Mahadik K, Zhang L, Kokare C: Production and stability studies of the biosurfactant isolated from marine Nocardiopsis sp. B4. Desalination 2012, 285:198-204.

3. Kiran GS, Selvin J, Manilal A, Sujith S: Biosurfactants as green stabilizer for the biological synthesis of nanoparticles. Crit Rev Biotechnol 2011, 31:354-364.

4. Haferburg $\mathrm{G}$, Kothe E: Microbes and metals: interactions in the environment. J Basic Microbiol 2007, 47:453-467.

5. Kiran GS, Sabu A, Selvin J: Synthesis of silver nanoparticles by glycolipid biosurfactant produced from marine Brevibacterium casei MSA19. J Biotechnol 2010, 148:221-225.

6. Kiran GS, Anto Thomas T, Selvin J: Production of a new glycolipid biosurfactant from marine Nocardiopsis lucentensis MSA04 in solid-state cultivation. Coll Surf B: Biointerf 2010, 78:8-16.

7. Makkar RS, Cameotra SS: An update on the use of unconventional substrates for biosurfactants production and their new applications. Appl Microbiol Biotechnol 2002, 58:428-434.

8. Flores M, Colon N, Rivera O, Villalba N, Baez Y, Quispitupa D, Avalos J, Perales O: A study of the growth curves of $C$. xerosis and $E$. coli bacteria in mediums containing cobalt ferrite nanoparticles. Mat Res Soc Symp Proc 2004, 820.

9. Merceda T, Santosa S, Riveraa O, Villalbaa N, Baeza Y, Gaudiera J, Avalosa J, Peralesa O, Tomara MS, Parra-Palominoa A, Avalos J: Effect of zinc oxide nanocrystals in media containing E. coli and C. xerosis bacteria. Mater Res Soc Symp Proc 2006, 900.

10. Das SK, Das AR, Guha AK: Gold nanoparticles: microbial synthesis and application in water hygiene management. Langmuir 2009, 25:8192-8199.

11. Sjogren CE, Johansson C, Naevestad A, Sontum PC, Saebo BK, Fahlvik AK: Crystal size and properties of superparamagnetic iron oxide (SPIO) particles. Magn Reson Imaging 1997, 15:55-67.

12. Perez JM, O'Loughin T, Simeone FJ, Weissleder R, Josephson L: DNA-based magnetic nanoparticle assembly acts as a magnetic relaxation nanoswitch allowing screening of DNA cleaving agents. J Am Chem Soc 2002, 124:2856-2857.

13. Fayati MD, Rahe EK, Md Angazi AT, Alizeh SK, Barani HN: The effect of magnetic Fe3o4 nanoparticles on genetically manipulated bacterium, Pseudomonas aeruginosa (P SOX4). Iran J Biotech 2013, 11:41-46.

14. Liu J, Vipulanandan C, Cooper TF, Vipulanandan G: Effects of Fe nanoparticles on bacterial growth and biosurfactant production. J Nanopart Res 2013, 15:1405.

15. Montalvo NF, Mohamed NM, Enticknap JJ, Hill RT: Novel actinobacteria from marine sponges. Antonie Van Leeuwenhoek 2005, 87:29-36.

16. Selvin J, Shanmughapriya S, Gandhimathi R, Seghal KG, Rajeetha Ravji T, Natarajaseenivasan K, Hema TA: Optimization and production of novel antimicrobial agents from sponge associated marine actinomycetes Nocardiopsis dassonvillei MAD08. Appl Microbiol Biotechnol 2009a, 83:435-445.

17. Meyer B, Kuever J: Phylogenetic diversity and spatial distribution of the microbial community associated with the caribbean deep-water sponge Polymastia cf. corticata by $16 \mathrm{~S}$ rRNA, aprA, and amoA gene analysis. Microbial Ecol 2007, 56:306-321.

18. Blanco M, Meira A, Baldomir D, Rivas J, Lopez MA: UV-VIS spectra of small iron particles. IEEE Trans Mag 1994, 30:739-741.

19. Chae SR, Therezien M, Budarz JF, Wessel L, Lin S, Xiao Y, Wiesner MR: Comparison of the photosensitivity and bacterial toxicity of spherical and tubular fullerenes of variable aggregate size. J Nanopart Res 2011, 13:5121-5127.

20. Sadiq IM, Pakrashi S, Chandrasekaran N, Mukherjee A: Studies on toxicity of aluminum oxide $\left(\mathrm{Al}_{2} \mathrm{O}_{3}\right)$ nanoparticles to microalgae species: Scenedesmus sp. and Chlorella sp. J Nanopart Res 2011, 13:3287-3299.

21. Choi O, Yu CP, Fernandez GE, Hu ZQ: Interactions of nanosilver with Escherichia coli cells in planktonic and biofilm cultures. Water Res 2010, 44:6095-6103.

22. Li F, Lei C, Shen Q, Li L, Wang M, Guo M, Huang Y, Nie Z, Yao S: Analysis of copper nanoparticles toxicity based on a stress-responsive bacterial biosensor array. Nanoscale 2013, 5:653-662.

23. Ehrlich HL: Microbes and metals. App/ Microbiol Biotechnol 1997, 48:687-692.

24. Hommel RK, Ratledge C: Biosynthetic mechanisms of low molecular weight surfactants and their precursor molecules. In Biosurfactant: Production, properties and applications. Edited by Kosaric N. Marcel Bekker Inc NY; 1993:3-63.

25. Bagg A, Neilands JB: Ferric uptake regulation protein acts as a repressor, employing iron II as a cofactor to bind the operator of an iron transporter operon in E.coliferric uptake regulation protein acts as a repressor, employing iron II as a cofactor to bind the operator of an iron transporter operon in E.coli. Biochem 1987, 2617:5471-5477.

26. Petersson G: Gas chromatography-mass spectrometry of sugars and related hydroxy acids as trimethylsilyl derivatives. Svensk Papperstidning 1974, 77:5.

27. Selvin J, Lipton AP: Vibrio alginolyticus associated with white spot disease of Penaeus monodon. Dis Aquat Org 2003, 57:147-150.

28. He F, Zhao D, Liu J, Roberts CB: Stabilization of Fe-Pd nanoparticles with sodium carboxymethyl cellulose for enhanced transport and dechlorination of trichloroethylene in soil and groundwater. Ind Eng Chem Res 2006, 46:29-34.

29. He S, Feng Y, Ren H, Zhang Y, Gu N, Lin X: The impact of iron oxide magnetic nanoparticles on the soil bacterial community. J Soils Sediments 2011, 11:1408-1417.

30. Selvin J, Thangavelu T, Kiran GS, Gandhimathi R, Shanmughapriya S: Culturable heterotrophic bacteria from the marine sponge Dendrilla nigra: isolation and phylogenetic diversity of actinobacteria. Hel Mar Res 2009, 63:239-247.

31. Selvin J, Soniya J, Asha KRT, Manjusha WA, Sangeetha VS, Jayaseema DM, Antony MC, Vinitha DAJ: Antibacterial potential of antagonistic Streptomyces $\mathrm{sp}$. isolated from the marine sponge Dendrilla nigra. FEMS Microbiol Ecol 2004, 50:117-122.

32. Morikawa M, Daido H, Takao T, Marato S, Shimonishi Y, Imanaka T: A new lipopeptide biosurfactant produced by Arthrobacter sp. strain MIS 38 . J Bacteriol 1993, 175:6459-6466.

33. Kiran GS, Hema TA, Gandhimathi R, Selvin J, Manilal A, Sujith $S$, Natarajaseenivasan K: Optimization and production of a biosurfactant from the sponge-associated marine fungus Aspergillus ustus MSF3. Coll Surf B: Biointerf 2009, 73:250-256.

34. Paraszkiewicz K, Kanwal A, Dlugonski J: Emulsifier production by steroid transforming filamentous fungus Curvularia lunata, growth and product characterization. J Biotechnol 1992, 92:287-294.

35. Lechevalier MP: Ecological associations involving actinomycetes. In Actinomycetes. Edited by Schaal KP, Pulverer G. Stuttgart: Gustav Fischer Verlag; 1981:159-166.

36. Ferrara GB, Murgia B, Parodi AM, Valisano L, Cerrano C, Palmisano G, Bavestrello G, Sara M: The assessment of DNA from marine organisms via a modified salting-out protocol. Cell Mol Biol Lett 2006, 11:55-160.

37. Kiran GS, Thomas TA, Selvin J, Sabarathnam B, Lipton AP: Optimization and characterization of a new lipopeptide biosurfactant produced by marine Brevibacteriumaureum MSA13 in solid state culture. Bioresour Technol 2010, 101:2389-2396.

38. Montgomery DC: Analysis and design of experiments. 4th edition. New York, NY: Wiley; 1997.

39. Neto DC, Meira JA, de Araujo JM, Mitchell DA, Krieger N: Optimization of the production of rhamnolipids by Pseudomonas aeruginosa UFPEDA 614 in solid-state culture. Appl Microbiol Biotech 2008, 81:441-448.

40. Dubois M, Gilies K, Hammilton JK, Robers PA, Smith FA: A colorimetric method for the determinationof sugars related substances. Anal Chem 1951, 28:350-356.

41. Benincasa M: Rhamnolipid production by $P$. aeruginosa LBI growing on soap-stock as the sole carbon source. J Food Eng 2002, 3:283-288.

doi:10.1186/1472-6750-14-48

Cite this article as: Kiran et al:: Effect of Fe nanoparticle on growth and glycolipid biosurfactant production under solid state culture by marine Nocardiopsis sp. MSA13A. BMC Biotechnology 2014 14:48. 